\title{
Kebijakan Luar Negeri Indonesia dalam Memberikan Bantuan Pengungsi Rohingya di Bangladesh
}

\author{
Dzikiara Pesona Sadewa ${ }^{1}$, Dudy Heryadi ${ }^{2}$, Taufik Hidayat ${ }^{3}$ \\ ${ }^{1}$ Fakultas Ilmu Sosial dan Ilmu Politik,Universitas Padjadjaran, Indonesia, dzikiara_kiki@yahoo.co.id \\ ${ }^{2}$ Fakultas Ilmu Sosial dan Ilmu Politik,Universitas Padjadjaran, Indonesia, dudy.heryadi@unpad.ac.id \\ ${ }^{3}$ Fakultas Ilmu Sosial dan Ilmu Politik, Universitas Padjadjaran, Indonesia, \\ taufik_hidayat_hi@yahoo.com
}

\begin{abstract}
ABSTRAK
Pasca konflik yang terjadi di Myanmar, khususnya di wilayah Rakhine, menyebabkan etnis Rohingya memilih untuk mengungsi ke Bangladesh yang merupakan negara yang paling dekat dengan Myanmar. Namun yang menjadi permasalahannya adalah kedatangan para pengungsi Rohingya di Bangladesh mengalami peningkatan dari tahun ke tahun sehingga mengakibatkan terjadinya penumpukan pengungsi. Bangladesh juga merupakan salah satu negara yang memiliki wilayah yang kecil namun memiliki penduduk yang padat. Para pengungsi Rohingya yang berdatangan mengalami kondisi yang memprihatinkan, mulai dari kelaparan hingga gizi buruk. Penelitian ini menjelaskan bagaimana kebijakan luar negeri Indonesia dalam memberikan bantuan para pengungsi Rohingya di Bangladesh. Kedua negara memiliki permasalahan yang sama dalam menangani pengungsi Rohingya yang datang ke negaranya sehingga ketika pemerintah Bangladesh membutuhkan bantuan, Indonesia memberikan kontribusinya berasaskan jiwa kemanusiaan. Penelitian ini menggunakan metode kualitatif. Penelitian ini menggunakan analisa yang diambil dari studi pustaka serta informasi tambahan dari situs resmi online pemerintahan dari kedua negara yaitu Indonesia dan Bangladesh. Selain itu, peneliti juga menggunakan beberapa literatur jurnal penelitian terdahulu terkait urgensi dan kondisi yang dialami oleh etnis Rohingya dan lalu dianalisa dengan konsep kebijakan luar negeri dari Rosenau dalam melihat bagaimana kebijakan luar negeri Indonesia dalam memberikan bantuan pengungsi Rohingya di Bangladesh. Hasil dari peneltian ini menunjukan bahwa Indonesia memberikan manfaatnya untuk mempererat kerjasama kedua negara dan juga memperkecil jumlah korban etnis Rohingya yang berjatuhan di Bangladesh.
\end{abstract}

Kata Kunci : kebijakan luar negeri; Indonesia; Bangladesh; Rohingya

\begin{abstract}
After the conflict that occurred in Myanmar, especially in the Rakhine region, the Rohingya chose to flee to Bangladesh, which is the country closest to Myanmar. But the problem is that the arrival of Rohingyadi refugees in Bangladesh has increased from year to year, resulting in a buildup of refugees. Bangladesh is also one of the countries that have a small area but has a densely populated population. Rohingya refugees who arrived were experiencing appalling conditions, ranging from hunger to malnutrition. This study explains Indonesia's foreign policy in providing assistance to Rohingya refugees in Bangladesh because both countries have the same problem in dealing with Rohingya refugees who come to their countries. So when the government of Bangladesh needs help to solve their refugee crisis, Indonesia is willing to provide its assistance because based on a humanitarian spirit. This study uses a qualitative method. This research uses analysis taken from library study data as well as additional information from the official online government sites of the two countries, Indonesia and Bangladesh. Besides that, the authors also use preceeding literatures from research journals related to the urgency and conditions experienced by Rohingya. Then, the authors analyze using the concept of foreign policy from Rosenau in seeing how Indonesia's foreign policy in providing Rohingya refugees in Bangladesh. The results of this study show that Indonesia provides benefits because it can strengthen cooperation between the two countries and also can reduce the number of ethnic victims Rohingyas that fell in Bangladesh.
\end{abstract}

Keywords : foreign policy; Indonesia; Bangladesh; Rohingya 


\section{Pendahuluan}

Tulisan ini memaparkan bagaimana kebijakan luar negeri Indonesia dalam memberikan bantuan pengungsi Rohingya di Bangladesh. Kedua negara pada dasarnya memiliki permasalahan yang sama terkait pengungsi Rohingya yang berdatangan ke negaranya sehingga kedua negara mulai menjalin hubungan yang baik dalam menangani pengungsi. Permasalahan yang dialami oleh etnis ini berawal dari perlakuan diskriminasi yang dialaminya selama berpuluhpuluh tahun yang lalu di Myanmar. Sekitar 100.000 orang Rohingya dibantai dan dipersempit ruang tinggalnya. Etnis ini juga mendapatkan diskriminasi verbal maupun nonverbal, bahkan Presiden Thein Sein ketika itu mempunyai solusi tersendiri dalam menyikapi permasalahan etnis Rohingya, yaitu dengan cara mendeportasinya. Hingga sekarang, masih belum ada satu negara yang benar-benar memberikan hak kewarganegaraan kepada etnis Rohingya. Munculnya kebijakan baru, yaitu Burma Citizen Law 1982 memberikan kerugian terhadap etnis Rohingya dikarenakan etnis ini tidak masuk dalam daftar sebagai etnis resmi di Myanmar dengan anggapan bahwa etnis ini bukanlah bagian dari Myanmar melainkan imigran gelap yang datang dari Bangladesh. Pada tahun 2012, terjadi konflik yang besar dalam tataran dunia internasional. Pasca konflik tersebut, 624.000 penduduk etnis Rohingya memilih mengungsi ke Bangladesh untuk mencari perlindungan. Namun yang menjadi persoalan di sini adalah banyak warga lokal yang menolak akan kehadirannya. Di Bangladesh sendiri sudah terjadi penumpukan penduduk di kamp pengungsi dan warga lokal Bangladesh sendiri masih sulit dalam mendapatkan berbagai akses bantuan seperti air minum, makanan, tempat tinggal, dan fasilitas kesehatan. Hal tersebut juga diperkuat dengan pernyataan dari PBB yang mengatakan bahwa sekitar 1,2 juta orang di Bangladesh diperkirakan membutuhkan bantuan pangan yang mencakup bukan hanya para pengungsi saja tetapi juga masyarakat lokal dari
Bangladesh. Hal tersebutlah yang menjadi alasan mengapa masyarakat di Bangladesh menolak untuk menampung pengungsi Rohingya yang datang ke negaranya karena dianggap akan semakin menghambat upaya negara untuk memenuhi kebutuhan pangan warganegaranya. ${ }^{1}$

Dengan demikian, para pengungsi Rohingya masih memerlukan bantuan dan perlindungan dengan didasari asas jiwa kemanusiaan. Kedatangan para pengungsi yang tiba di Bangladesh menjadi salah satu fokus negara dalam mengatasinya. Ketika tiba di Bangladesh, para pengungsi berada dalam kondisi yang memprihatinkan, yakni dilanda banyak penyakit dan kesehatan yang buruk, terutama para pengungsi yang datang di Cox's Bazar. Hal tersebut dapat dilihat sebagai berikut: Berawal dari tingkat kesehatan etnis Rohingya yang buruk di Myanmar yang terindeksi Global Acute Malnutrition (GAM) dan Severe Acute Malnutrition (SAM) dengan mencapai angka sebanyak $24,9 \%$ dan $4,7 \%$ di wilayah Rakhine, selain itu juga Di kampkamp yang ditangani oleh UNHCR di temukan banyak yang menderita GAM sebanyak 13\% dan stunting $(42,9 \%)$ hal tersebut sudah dialami selama 6-59 bulan dan diperkirakan juga terdapat 240.000 anak membutuhkan nutrisi dan pemenuhan gizi yang cukup di wilayah Rakhine di Myanmar. Banyak juga bayi yang lahir dari keluarga yang berketurunan Rohingya yang menderita penyakit Prevalensi Wasting yang didisebabkan oleh malnutrisi akut dan merupakan prediktor kuat kematian di antara anak-anak di bawah 5 tahun. Prevalensi malnutrisi akut ini banyak dialami oleh Rohingya di wilayah utara Negara Bagian Rakhine WHO sebagai organisasi kesehatan

\footnotetext{
${ }^{1}$ The Guardian News, (2018, 25 November) UN report on Rohingya hunger is shelved at Myanmar's request. Diakses melalui https://www.the guardian. com/world/2017/ oct/17/un-report-on-rohingya hunger -isshelved-atmyanmars-request
} 
mengatakan bahwa etnis ini membutuhkan bantuan makan yang cukup dan memadai dengan disertai asupan makanan yang bergizi untuk memperkecil korban yang terus berjatuhan.

Hal tersebut berlanjut ketika para pengungsi Rohingya yang tiba di Cox's Kamp Distrik Bazar yang dihadapkan dengan kondisi yang sama disertai dengan kondisi kemiskinan yang ekstrem serta dihadapkan juga dengan penyakit seperti Stunting yang disebabkan oleh kekurangan gizi, campak dan kelaparan Medecins Sans Frontieres (MSF) mencatat bahwa terdapat sepuluh kali lipat peningkatan angka kematian terhadap etnis Rohingya yang tinggal di pengungsian dan mereka juga mendapatkan keadaan darurat kesehatan dan masalah gizi yang serius di Cox's Bazar terutama terhadap anak-anak di pengungsian. Terdapat juga beberapa penelitian terdahulu yang sudah dilakukan dalam memaparkan fenomena kelaparan dan gizi buruk yang dialaminya etnis Rohingya di Bangladesh seperti yang ditulis oleh Marjke Wijnrorks, Martin W. Bloem dkk dengan judul Surveillance of the Health and Nutritional Status of Rohingya Refugees in Bangladesh. Di dalam penelitian tersebut telah ditemukan sekitar 263.000 pengungsi Rohingya mengalami kekurangan nutrisi yang pada akhirnya menderita gizi buruk akibat hal tersebutlah banyak pengungsi Rohingya yang meninggal di Bangladesh. Penelitian yang kedua yang telah ditulis oleh Emily Y.Y Chan, Cheuk Pong Chiu dkk dengan judul Medical and health risks associated with communicable diseases of Rohingya refugees in Bangladesh 2017. Di dalam penelitian tersebut telah ditemukan pengungsi Rohingya yang menderita berbagai penyakit di camp Bangladesh mulai dari diare, gizi buruk dan sebagainya di tahun 2017, mereka membutuhkan bantuan medis serta makanan yang cukup dikarenakan di sana masih adanya keterbatasan dalam akses medis maupun makanan.
Dalam melihat fenomena diatas menjadi sebuah keprihatinan tersendiri bagi Indonesia yang pada dasarnya negara ini memiliki tingkat kepedulian yang tinggi terhadap para pengungsi Rohingya hal tersebut juga ditunjukkan dengan berbagai upaya nyata yang dilakukannya. Berdasarkan hal tersebut maka penelitian ini bertujuan untuk mengetahui bagaimana kebijakan luar negeri Indonesia dalam memberikan bantuan para pengungsi Rohingya di Bangladesh.

\section{Metode penelitian}

Metode yang digunakan di dalam penelitian ini adalah dengan metode penelitian kualitatif Metode ini dipilih dikarenakan dengan metode ini peneliti dapat menyoroti masalah dengan perilaku dan peran dari negara, sehingga penelitian menggunakan analisa yang diambil dari data-data studi pustaka serta informasi tambahan dari situs resmi online pemerintahan dari kedua negara yaitu Indonesia dan Bangladesh, selain itu juga peneliti menggunakan beberapa literatur jurnal penelitian terdahulu terkait urgensi dan kondisi yang dialami oleh etnis Rohingyaa di Bangladesh untuk melihat mengapa etnis ini harus di berikan bantuan. Penelitian ini juga dianalisa menggunakan konsep kebijakan luar negeri yang diutarakan oleh Rosenau dalam melihat bagaimana kebijakan luar negeri Indonesia dalam memberikan bantuan pengungsi Rohingya di Bangladesh

\section{Tinjauan Pustaka}

\section{Kebijakan Luar Negeri}

Kebijakan Luar negeri berkaitan dengan politik luar negeri, Miriam Budiarjo memberikan pandangannya bahwa politik luar negeri berperan sebagai kebijakan (policy) yang menjadi kumpulan yang ditetapkan oleh para pelaku atau kelompok dalam upaya mencapai tujuan tertentu, di mana pada akhrinya kebijakan tersebut dapat memunculkan kekuasaan untuk melaksanakannya. 
92 Dzikiara Pesona Sadewa, Dudy Heryadi dan Taufik Hidayat | Kebijakan Luar Negeri Indonesia dalam Memberikan Bantuan Pengungsi Rohingya di Bangladesh

Tabel 1. Kondisi kesehatan pengungsi

\begin{tabular}{|c|c|c|c|c|}
\hline & $\begin{array}{l}\text { Cox's Bazar District } \\
\text { Host Population }\end{array}$ & $\begin{array}{l}\text { Rohingya Refugees } \\
\text { In Camps }\end{array}$ & Bangladesh & $\begin{array}{l}\text { Myanmar } \\
\text { (Rakhine state) }\end{array}$ \\
\hline Demographics & pop $=2.28$ million & pop $=915,000$ & & \\
\hline M:F & $1.04: 1$ & $0.95: 1$ & 0.97:1 & 0.93:1 \\
\hline Under 5 & $13.3 \%$ & $18 \%$ & - & $17 \%$ \\
\hline Under 15 & $43 \%$ & $55 \%$ (U18) & $29 \%$ & $27 \%(31 \%)$ \\
\hline 60 and above & $5.1 \%$ & $3 \%$ & $7.5 \%$ & $8.8 \%(6 \%)$ \\
\hline \multicolumn{5}{|l|}{ Adult Health } \\
\hline Diabetes & -- & -- & $7 \%$ & $4.6 \%$ \\
\hline Hypertension & -- & -- & female $32 \% ;$ male $19 \%$ & -- \\
\hline Obesity & -- & -- & $3.6 \%$ & $5.8 \%$ \\
\hline Disability rate & $1.5 \%$ & $4 \%$ & $9 \%$ & $4.8 \%(5.3 \%)$ \\
\hline \multicolumn{5}{|l|}{ other } \\
\hline Adult literacy & $\begin{array}{l}38.2 \% \text { female; } 40.3 \% \\
\text { male; } 39.3 \% \text { all }\end{array}$ & $\begin{array}{l}\text { estimated at less } \\
\text { than } 20 \%\end{array}$ & $\begin{array}{l}70 \% \text { female; } 76 \% \text { male; } \\
73 \% \text { all }\end{array}$ & $\begin{array}{l}72 \% \text { female; } 80 \% \text { male; } \\
76 \% \text { all }\end{array}$ \\
\hline GDP per capita (USD) & -- & - & $\$ 1,544$ & $\$ 1,195$ \\
\hline \multicolumn{5}{|l|}{ Child Health } \\
\hline $\begin{array}{l}\text { Low birth weight } \\
\text { deliveries }\end{array}$ & $32.3 \%$ & -- & $26 \%$ & $8 \%$ \\
\hline $\begin{array}{l}\text { Exclusive breastfeeding } \\
\text { (under } 6 \text { mo.) }\end{array}$ & -- & -- & $56 \%$ & $24 \%(1.3 \%)$ \\
\hline $\begin{array}{l}\text { Infant Mortality Rate } \\
\text { (IMR) }\end{array}$ & - & - & 29 & $41(61)$ \\
\hline $\begin{array}{l}\text { Under } 5 \text { Mortality Rate } \\
\text { (U5MR) }\end{array}$ & - & - & $36 ; 56$ rural areas & $53(71)$ \\
\hline U5 stunting & $49.5 \%$ & over $40 \%$ & $36.1 \%$ & $29.2 \%(42.9 \%)$ \\
\hline U5 wasting & $10.1 \%$ & $24.3 \%$ ( $7.3 \%$ severe) & $14 \%$ & $7 \%$ \\
\hline U5 underweight & $40.5 \%$ & & $32.6 \%$ & $18.996(41.6 \%)$ \\
\hline Measles imm. coverage & - & $96 \%$ & $86 \%$ & $77.3 \%$ \\
\hline Vit. A supp. coverage & -- & $95 \%$ & $62 \%$ & $54 \%$ \\
\hline $\begin{array}{l}\text { Diarrhea } \\
\text { (U5 in past } 2 \text { weeks) }\end{array}$ & - & - & $3.9 \%$ & - \\
\hline
\end{tabular}

Sumber : $(\text { Seva and IAPB })^{2}$

Selain itu juga bahwa dalam memahami politik luar negeri selalu berkaitan terhadap dua aspek yaitu aspek eksternal dan internal suatu negara yang membentuk kebijakan suatu negara untuk dapat mengatur hubungan antara satu dengan yang lainnya di dalam lingkup dunia internasional. dengan kata lain bahwa politik luar negeri berbeda beda antara satu negara dengan negara lainnya tergantung dari masingmasing tujuan nasional negara yang ingin dicapainya. Rosenau mendefinisikan bahwa kebijakan luar negeri menjadi salah satu langkah atau upaya pemerintah dalam mengambil tindakan dalam guna melindungi aspek-aspek penting yang terdapat di suatu negara dari berbagai lingkup pengaruh lingkungan internasional ataupun dari berbagai kebijakan diambil untuk mengubah beberapa aspek yang tidak diinginkan Rosenau menjelaskan terdapat tiga konsep dasar dalam memahami kebijakan luar negeri, ialah sebagai berikut, yakni Pengambilan kebijakan luar negeri harus mengacu pada sikap, persepsi, dan nilai-nilai yang dianut oleh sebuah negara dimana semua hal ini berasal dari pengalaman sejarah negara dan posisi strategis negara tersebut dalam percaturan politik internasional. selain itu juga dalam konsep dari kebijkan luar negeri yang di utarakan Rosenau ${ }^{2}$ memberikan tiga unit analisis kebijkan luar negerinya yakni orientasi (foreign Policy as a set of orientations) komitmen dan rencana aksi ( Foreign policy as a set of commitments to and plans for action dan Perilaku (foreign policy as a form of behaviour).

2 James $\mathrm{N}$ Rosenau, World Politics; an introduction (pp. 16). New York: The Free Press. 1976. 
Orientasi tersebut juga merupakan kecenderungan umum yang dapat mengarahkan negara dalam melakukan hubungan internasional. Orientasi tersebut meliputi sikap, persepsi dan nilai nilai yang berasal dari pengalaman historis dan lingkungan strategis dari masyarakat di dalam negara. Komitmen dan aksi tersebut merupakan rencana dalam merespon situasi luar yang berdasarkan konsistensi dengan orientasi dasar, meliput strategi, keputusan dan kebijakan kebijakan yang terakhir perilaku merupakan aktivitas dari langkah nyata resmi yang berkaitan dengan peristiwa dan situasi tertentu dalam melakukan sesuatu untuk tidak melakukan sesuatu dalam berinteaksi dengan aktor-aktor lain (Individu, kelompok, negara, dan lainnya) sehingga kemudian unit unit analisis tersebut kemudian dipilh ke dalam level dari kebijakan luar negeri memiliki 3 tahap diantaranya adalah nasional, regional, dan global.

Dalam level nasional, akuantibilitas politik, struktur pemerintah, dan kepribadian pemimpin yang meliputi dari nilai, talenta dan pengalaman yang pada akhirnya dapat mempengaruhi kebijakan luar negeri.ukuran geografis juga akan dapat mempengaruhi level regional dan global. Pada level regional yang dapat mempengaruhinya diantaranya adalah kebudayaan, sejarah, struktur sosial, situasi intrnal regional, dan juga pembangunan ekonomi. Sementara itu dalam tataran sistem, selain ukuran geografi, struktur aliansi negara negara adidaya dan situasi eksternal (seperti area isu dan krisis) sangat mempengaruhi kebijkan luar negeri suatu negara terhadap level level analisis. ${ }^{3}$

\section{Human Security}

Human Security pada dasarnya menekankan terhadap bentuk keadilan dan emansipasi dalam upaya menghubungkan politik domestik dalam hubungan internasional, oleh karena itulah dalam melihat gagasan yang di anut dalam konsep Human Security pada umunya menghadapkan

\footnotetext{
${ }^{3}$ Deasy Silvya Sari, Kebijakan Luar Negeri Indonesia Terhadap Mesir Pasca Pemerintahan Husni Mubarak (pp. 18). Bandung: Universitas Padjadjaran. 2018.
}

negara di dalam kedaulatann setiap individu warga negaranya. Saat ini Human Security mulai berusaha menggeser terhadap pemikiran keamanan dan mengandung beberapa sectorsektor seperti sektor sosial, psikologi, politik, dan ekonomi yang berfokus dalam mendukung serta menjaga keamanan dalam menciptakan kesejahteraan manusia. selain itu juga dalam melihat konsep ini tidak hanya melihat bagaimana cara menjaga keamanan manusia di dalam kurun waktu tertentu saja tetapi juga mencari cara bagaimana mempertahankan kondisi keamanan tersebut dalam setiap waktu agar kehidupan manusia tidak terancam dan tidak juga terlanggar atas hak yang dimilikinya.

Konsep ini di kenalkan oleh United Nations Development Programme (UNDP) dalam Human Development Report 1994. Di dalam laporannya tersebut berisikan bahwa sebagai suatu konsep kemanan, human security terdiri dari 2 aspek diantaranya adalah yang pertama berkatian dengan ancaman kronoik yang ada saat ini seperti kelaparan, penindasan dan penyakit, dan yang kedua berkaitan dengan aspek masalah kesejahteraan sosial, serta perlindungan terhadap kelompok minoritas, masalah-masalah sosial, ekonomi, dan politik namun ketika pasca perang dingin telah memunculkan pemahaman baru bahwa cara-cara melibatkan militer tidak dapat digunakan lagi dalam mengatasi konflik internasional di karenakan mengingat bahwa akar masalah dari konflik itu sangat luas dan kompleks. Oleh karena itu cara dalam menyelesaikan konflik tersebut bersumber dari masalah di dalam aspek politik, ekonomi, sosial budaya, agama, lingkungan hidup. ${ }^{4}$ Oleh karena itulah UNDP (1994) telah merinci 7 komponen aspek human security yang sangat penting untuk di pahami diantaranya adalah

1) economic security (yang artinya bahwa

4 United Nations. Development Programme (UNDP). Human Development Reports (pp 229-236). New York. Oxford. Oxford University Press. 1994. 
keamanan terhadap kebebasan dari ekonomi mulai dari faktor kemiskinan serta juga pemenuhan biaya untuk hidup,

2)

food security (yaitu adanya kemudahan dalam akses kebutuhan pangan)

3) health security (yang artinya adanya kemudahan dalam mendapatkan berbagai layanan kesehatan dan juga perlindungan terhadap berbagai penyakit)

4)

environmental security (yang artinya adanya proteksi terhadap pencemaran lingkungan, serta adanya akses terhadap air)

5)

personal security (yang artinya harus adanya keselamatan dari ancaman fisik yang diakibatkan oleh berbagai faktor misalnya perang, kekerasan kriminalitas, penggunaan obat-obatan terlarang, dan juga bahkan Kecelakaan yang di sebabkan lalu lintas),

6)

community security (artinya harus adanya keamanan dalam kelestarian terhadap identitas kultural dan berbagai tradisi budaya yang di punyainya)

7)

political security (yang artinya hal keamanan politik di sini memerlukan perlindungan dalam hak asasi manusia dan juga dalam kebebasan dari tekanan politik). ${ }^{5}$ Dalam penelitian ini menjelaskan bahwa Indonesia memberikan bantuan secara sosial hal tersebut dilakukan berdasarkan atas jiwa kemanusiaannya dalam membantu serta memberikan perlindungan pengungsi Rohingya di Bangladesh.

\section{Pembahasan}

Bangladesh menjadi satu negara di kawasan Asia selatan yang terletak di dataran

\footnotetext{
5 Trust Fund for Human Security, (2019, 3 Juni) Human Security in Theory and Practice, Application of the Human Security Concept and the United Nation. Diakses melalui <http://hdr.undp.org/en/media/HS_Handbo ok_2009.pdf>
}

rendah berhubungan dengan sungai sungai yang besar. Bangladesh juga merupakan negara yang kaya akan sumber daya alam di karenakan letaknya yang cukup strategis, namun di sisi lain akibat letaknya yang cukup strategis tersebut pada akhirnya negara ini sering kali menimbulkan bencana alam yang rawan sekali terkena bencana alam seperti banjir dan biasanya juga diselingi dengan di peparahnya angin muson oleh karena itulah terkadang penduduk asli dari Bangladesh memiliki tingkat masalah kesehatan dan kelaparan akibat ketersediaan pangannya tidak cukup akibat produktivitas di sektor pertanian kurang opimal akibat bencana alam sehingga pada akhirnya mereka juga membutuhkan bantuan dari negara lain.

Tingkat kemiskinan yang cukup tinggi menjadi permasalahan yang cukup serius di Bangladesh, dimana ditemukannya banyaknya pengangguran di negara ini, hal tersebut juga di perkuat dengan data yang diperoleh dari World Bank yang telah menunjukan bahwa sekitar $40 \%$ dari populasi penduduk yang berada di Bangladesh telah masuk di bawah garis kemiskinan, kemiskinan tersebut juga disebabkan oleh beberapa faktor diantaranya adalah instabilitas politik, masalah ekonomi, bencana alam dan juga dikarenakan minimnya fasilitas umum $^{6}$ negara ini juga mempunyai populasi penduduk hampir mencapai 164 juta orang dan juga menempati penduduk terbanyak ke 8 di dunia sekaligus juga menjadi negara yang terpadat di dunia hal tersebut yang dianggap menjadi permasalahan dikarenakan dengan penduduknya yang padat, tidak didukung dengan wilayah yang besar karena Bangladesh merupakan wilayah yang relatif kecil dengan penduduk yang padat.

\footnotetext{
${ }^{6}$ The World Bank (2019, 1 Juni) Bangladesh World Development Indicators. Diakses melalui<http://data.worldbank.org/country/ bangladesh $>$
} 
95 Dzikiara Pesona Sadewa, Dudy Heryadi dan Taufik Hidayat | Kebijakan Luar Negeri Indonesia dalam Memberikan Bantuan Pengungsi Rohingya di Bangladesh

Rohingya refugees reported by location

\begin{tabular}{|lll|}
\hline Location & Population prior to Aug Influx & $\begin{array}{l}\text { Total Population as of 24 March } \\
\text { (combined) }\end{array}$ \\
\hline Kutupalong Expansion Site ${ }^{1}$ & 99,705 & 584,069 \\
\hline Kutupalong RC & 13,901 & 13,634 \\
\hline Leda MS & 14,240 & 9,763 \\
\hline Nayapara RC & 19,230 & 26,960 \\
\hline Camp 14 (Hakimpara) & 140 & 34,181 \\
\hline Unchiprang & - & 22,176 \\
\hline Camp 15 (Jamtoli) & 72 & 46,666 \\
\hline Camp 16 (Bagghona/Potibonia) & 50 & 21,665 \\
\hline Chakmarkul & - & 11,967 \\
\hline Grand Total & $\mathbf{1 4 7 , 3 3 8}$ & $\mathbf{7 7 1 , 0 8 1}$ \\
\hline Refugee in Host Communities & & \\
\hline Cox's Bazar Sadar & 12,485 & 5,476 \\
\hline Ramu & 1,600 & 1,973 \\
\hline Teknaf & 42,870 & 102,665 \\
\hline Ukhia & 8,125 & 2,673 \\
\hline Grand Total & $\mathbf{6 5 , 0 8 0}$ & $\mathbf{1 1 2 , 7 8 7}$ \\
\hline TOTAL Rohingya & $\mathbf{2 1 2 , 5 1 8}$ & $\mathbf{8 8 3 , 8 6 8}$ \\
\hline
\end{tabular}

\section{$\underline{\text { Sumber: }(\mathrm{ISCG})^{10}}$}

Selain itu juga negara ini memiliki permasalahan lain karena berbatasan dengan negara Myanmar sehingga banyak para pengungsi yang berdatangan dari Myanmar khususnya enis Rohingya yang sering terjadinya konflik yang berkepanjangan ini akibat dari permasalahan perbedaan suku dan agama, mayoritas penduduk di Negara Bagian Rakhine yang beragama Buddha, sedangkan Muslim Rohingya adalah etnis minoritas yang beragama Muslim. Banyak etnis Rohingya yang ditolak keberadaannya dan sampai saat ini juga etnis ini tidak diberikan kewarganegaraan oleh pemerintah. ${ }^{7}$

Sejak tahun 1992 pengungsi Rohingya terus mengalami peningkatan mereka melarikan diri dari negara Myanmar dan memasuki distrik Cox's Bazar di Bangladesh. Pemerintah Bangladesh ketika itu menanggapi masuknya para pengungsi secara positif dengan berfokus memberikan mereka tempat tinggal dan makan namun lama

${ }^{7}$ Chit and Thomas Kean, "Communal Conflict in Myanmar: The Legislature's Response." Journal of Contemporary Asia 47 (3): (2017): 2012-2015. DOI:10.1080/ 004723 36.2017 .1291847 kelamaan pengungsi Rohingya mengalami peningkatan hampir sekitar 263,291 (UNHCR, 1992).

Seorang wartawan yang sedang berada di Cox's Bazaar, Bangladesh, memberikan kesaksiannya bahwa dia melihat terdapat ribuan para pengungsi Rohingya yang datang dengan cara membanjiri pintu masuk di wilayah perbatasan dan hal tersebut dianggap sangat memprihatinkan karena tidak adanya upaya dalam penghentian para pengungsi oleh para petugas dari Bangladesh. PBB memperkirakan para pengungsi Rohingya yang berhasil menyeberangi perbatasan hampir sekitar 58.000 pengungsi. $^{8}$

Dari tahun ke tahun para pengungsi Rohingya yang datang ke Bangladesh memiliki peningkatan yang signifikan. Hal tersebutlah yang pada akhirnya memberikan tekanan terhadap pemerintah Bangladesh dan mereka pada akhirnya meminta bantuan internasional untuk membantu

${ }^{8}$ BBC News, (2018, 28 November). Polisi Bangladesh abaikan perintah, pengungsi Rohingya membanjir masuk. Diakses melalui https:// www.bbc.com/ indonesia/ dunia-41139299 
Pemerintah dalam menangani jumlah pengungsi Rohingya yang masuk ke Bangladesh. Hal tersebut lah yang menjadi permasalahan bagi pemerintah Bangladesh dalam menyikapinya dikarenakan menyebabkan terjadinya penumpukan camp pengungsi. Di tahun 2018 terjadi peningkatan pengungsi di beberapa wilayah di Bangladesh dikarenakan adanya kekerasan yang diterima di negara Myanmar tidak kujung usai dari tahun ke tahun, yang pada akhirnya Rohingya lebih memilih untuk menetap di Bangladesh dikarenakan jaraknya yang begitu dekat di beberapa titik seperti berikut: Pemerintah Bangladesh telah membantu Rohingya sejak tahun 1992 dan membangun camp pengungsi di beberapa titik diantaranya adalah kamp Nayapara dekat kamp Teknaf dan Kutupalong dekat Ukhia untuk memberikan perlindungan kepada 21.621 pengungsi. Kamp Kutupalong secara resmi menampung 8.216 pengungsian Nayapara 13.405 , termasuk juga menjaga kondisi kesehatan dan makanan di camp para pengungsi. ${ }^{9}$ Menurut pemerintah dari Bangladesh kondisi yang dialami Rohingya merupakan kondisi yang sangat memprihatinkan dan mereka juga memiliki permasalahan kesehatan di kamp-kamp pengungsian. seperti pneumonia, bronkitis, serta penyakit kulit, Masalah lain juga ditemukan termasuk HIV, hepatitis dan penyakit kronis. Pada dasarnya Myanmar dan Bangladesh memiliki prevalensi HIV yang rendah di antara negaranegara Asia, namun provinsi Rakhine memiliki prevalensi tertinggi HIV di 2015. Selain itu, ditemukan juga para korban kekerasan seksual yang sudah terinfeksi oleh penyakit HIV sehingga kemudian menjadi permasalahan yang dihadapi pemerintah Bangladesh sehingga mereka membutuhkan peranan dari berbagai pihak di dunia internasional untuk membantunya hal tersebut. Hal ini terlihat dari kenaikan dari tahun ke tahun yang menyebabkan masalah penumpukan para pengungsi di tahun 2018 sebagai berikut:

\footnotetext{
${ }^{9}$ Medecins Sans Fronieres (MSF), 10 years For The Rohingya Refugees in Bangladesh, Past Present And Future (pp.12). 2012.
} 
97 Dzikiara Pesona Sadewa, Dudy Heryadi dan Taufik Hidayat | Kebijakan Luar Negeri Indonesia dalam Memberikan Bantuan Pengungsi Rohingya di Bangladesh

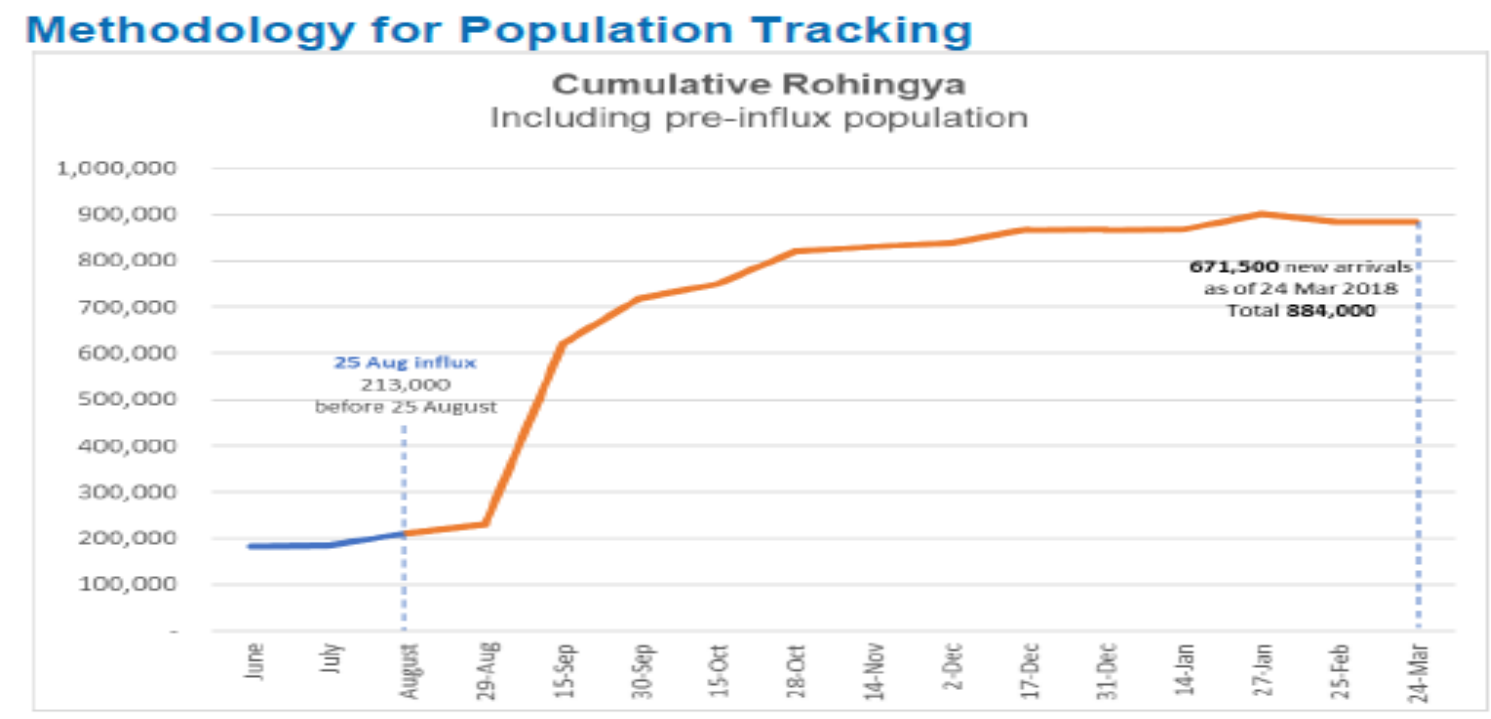

Pemerintah terus melakukan berbagai upayanya dalam membantu memberikan bantuan perawatan terhadap 300 pasien per hari, namun hal tersebut masih belum lah cukup dikarenakan membutuhkan dana dan peralatan medis yang memadai banyaknya Rohingya yang terkena penyakit juga disebabkan karena kurangnya pemenuhan gizi yang baik dan kualitas air yang buruk. Selain itu juga sekitar 42000 para wanita Pengungsi Rohingya yang sedang hamil dan $72.000 \mathrm{Ibu}$ yang menyusui membutuhkan bantuan kesehatan dan nutrisi yang baik dalam makanan tambahan yang bergizi. ${ }^{10}$

Indonesia juga merupakan negara yang sama khususnya mengenai masalah isu pengungsi Rohingya yang datang ke negaranya, contohnya adalah pengungsi Rohingya yang tiba di Aceh yang juga telah diselamatkan oleh orang Aceh dan lalu ada penanganan lanjut oleh pemerintah Indonesia dalam mengatur kebijakan teknis dalam penanganan para pengungsi Rohingya di Indonesia. Selain itu juga pemerintah

${ }^{10}$ Mohammad Mainul Islam, Tasmiah Nuzhath Health risks of Rohingya refugee population in Bangladesh: a call for global attention." Bangladesh: University of Dhaka. 2018. melakukan penanganan pengungsi di dalam kebijakan luar negerinya dalam kasus Rohingya secara bilateral, regional serta menjalin juga kerjasama dengan berbagai lembaga internasional. ${ }^{11}$ Dalam kasusnya yang terjadi di Bangladesh, Indonesia turut juga menjalin hubungan dan kerjasama dengan pemerintah Bangladesh dalam kebijakan luar negerinya, mengingat bahwa kedua negara ini merupakan negara yang memiliki permasalahan yang sama dalam menangani isu permasalahan pengungsi Rohingya yang terus berdatangan pasca konflik yang terjadi di Myanmar sehingga ini menjadi permasalahan yang harus diatasi oleh kedua negara baik Bangladesh maupun Indonesia Namun dalam kenyataannya, terjadi sebuah perbedaan antara kedua negara dimana secara umum Indonesia dapat mengatasi beberapa perihal permasalahan pengungsi Rohingya yang masuk terhadap negaranya berbeda dengan Bangladesh yang cukup memprihatinkan dikarenakan negara di kenal

${ }^{11}$ Deasy Silviya Sari, Taufik Hidayat dan Aliyuna Pratisti. Indonesian Government Policy on Rohingya Refugees. Andalas Journal of International Studies VII (1). 2018. DOI: https://doi.org/ 10.25077 /ajis.7.1.1-13.2018 
sebagai negeri yang miskin dan memiliki luas wilayah yang kecil namun memiliki jumlah penduduk hampir 150 juta jiwa. ${ }^{12}$ Dalam membantu pemerintah Bangladesh dalam memberikan bantuan terhadap etnis Rohingya, Indonesia mempunyai sebuah orientasi kebijakan luar negerinya berdasarkan dari asas kemanusiaan. Kemanusiaan merupakan sesuatu didasarkan dengan niat baik. Kemanusiaan bisa dikategorikan menjadi tiga hal. Yang pertama, kemanusiaan merupakan kekuatan yang membuat sebuah tujuan dan pilihan. Kekuatan ini pada dasarnya telah dimiliki oleh semua makhluk yang rasional. Kedua, adanya kesetaraan kelompok yang memiliki sifat atau kemampuan tertentu, yang dimiliki semua makhluk rasional karenanya semua makhluk rasional harus diperlakukan sesuai tujuan dalam diri mereka sendiri. Ketiga, manusia adalah kapasitas untuk bertindak secara moral.yang artinya terdapat kapasitas secara moralitas untuk menuntut tindakan moral serta menerima prinsip-prinsip moral sebagai penentu tindakan seseorang dalam menentukan setiap tindakannya. ${ }^{13}$ Kebijakan luar negeri yang dimiliki Indonesia adalah menganut pollitik bebas aktif dimana politik bebas aktif ini lahir keika Indonesia menjadi negara yang merdeka ketika itu dunia sedang ada berada dimana dengan kondisi sisem dunia yang bipolar. Dengan berawal dari munculnya negara adikuasa pemernang perang dari dunia ke 2 yaitu Amerika Serikat dan Uni Soviet, yang sama-sama melebarkan pemahamannya di berbagai negara, namun ketika itu Indonesia memilih untuk menjadi non-blok dan tidak memihak manapun, oleh karena itulah politik luar negeri Indonesia mulai menggunakan bebas aktif yang artinya

${ }^{12}$ Heru Susetyo, Heri Aryanto, Ryan Muthiara Wasti, Rohingya Suara Etnis yang Tidak Boleh Bersuara (pp. 40). Jakarta: PAHAM Indonesia. 2013.

${ }^{13}$ Richard Dean. The Value of Humanity: in Kan't Moral Theory. Oxford: Clarendon Press. 2006. tidak memihak salah satu blok kekuatan dan ingin menciptakan perdamian dunia.

Selain itu juga arah politik luar negeri Indonesia ketika di bawah pimpinan susilo Bambang Yudhoyono yang dikenal dengan kata berlayar di antara samudera yang bergolak yang artinya adalah dasar dari pergolakan yang saat ini tidak terlalu jelas hitam putihnya yang mengalami perubahan dan perkembangan yang cepat sehingga Indonesia mulai menggabungkan independensi dan diplomasi yang aktif yang pada akhirnya Indonesia memegang prinsip untuk tidak mengganggap negara lain sebagai musuh dan mencari kawan dengan sebanyak banyaknya ("zero enemy and thousand friends"). Dengan demikian, bahwa Indonesia berharap tidak memiliki musuh yang mengancam dan berharap agar negara negara di dunia dapat menjadikan Indonesia sebagai kawan bukan lawan ${ }^{14}$ Selain itu juga di era pemerintah Joko Widodo Kebijakan luar negeri Indonesia lebih mengedepankan politik bebas aktif ${ }^{15}$ yang ditujukan untuk :

1. Mengedepankan identitas sebagai negara kepulauan dilakukan dengan upaya diplomasi dan kerjasama internasional

2. Meningkatkan berbagai peran Indonesia secara global dengan melalui diplomasi middle power yang pada akhirnya menempatkan Indonesia menjadi kekuatan regional dan kekuatan global yang selektif dengan cara memberikan prioritas yang secara langsung juga berkaitan dengan berbagai kepentingan bangsa dan Indonesia

${ }^{14}$ Agus Haryanto. Prinsip Bebas Aktif Dalam Kebijakan Luar Negeri Indonesia: Perspekif Teori Peran. Jurnal Ilmu Politik dan Komunikasi, Universitas Komputer Indonesia IV (II). 2014.

${ }^{15}$ Mangadar Situmorang, Orientasi Kebijakan Politik Luar Negeri Indonesia di bawah Pemerintahan Jokowi-JK. Jurnal Ilmiah Hubungan Internasional 11 (1). 2015. DOI: https://doi.org/10.26593/jihi.v11i1.1442.\%2 $5 \mathrm{p}$ 
3. Memperluas berbagai keterlibatan regional di kawasan Indo-Pasifik

4. Merumuskan serta melaksanakan politik luar negeri dengan cara melibatkan terhadap berperan, aspirasi dan juga keterlibatan masyarakat.

Konsep dari Human Security menjadi dasar bagaimana kedua negara ini saling mendukung dalam mengatasi permasalahan etnis Rohingya antara satu sama lain, peran negara menjadi dasar sebuah paradigma dimana dengan adanya kerjasama yang dilakukan menjadi salah satu pilihan yang dianggap dapat menjadi solusi dalam menghadapi permasalahan yang di hadapi, dengan adanya ketidakstabilan negara penerima dipandang memiliki arti yang sangat penting dalam memahami perilaku masyarakat internasional karena menyangkut tentang jiwa kemanusiaan, etnis Rohingya yang datang ke Bangladesh menjadi salah satu bentuk kemanaan dan perlindungan dari political security, Health Secuirty dan Food Security mengingat adanya keterkaitan Hak asasi Manusia (HAM) di dalamnya, yang dimana HAM tercipta atas karunia yang diberikan oleh Tuhan yang harus dilindungi dijaga karena martabatnya sebagai manusia, dalam kasus yang dihadapi oleh Rohingya, kedua negara ini mencoba melindungi HAM terhadap etnis ini dalam mendapatkan bantuan makanan maupun kesehatan karena hal tersebut juga berasaskan dari jiwa kemanusiaan.

Selain itu juga dengan adanya kesamaan etnis dan agama yang dimiliki pemerintah Bangladesh menjadi tanggung moral sehingga bantuan oleh berbagai negara dan bantuan yang masuk melalui lembaga lembaga internasional diterima dengan harapan agar permasalahan tersebut dapat terselesaikan dan mengurangi korban yang berjatuhan, Indonesia merupakan salah satu negara yang memiliki jiwa kemanusiaan yang cukup tinggi itu terbuki ketika mereka dapat menerima para pengungsi Rohingya yang berdatangan ke negaranya, selain itu juga masyarakat banyak melakukan aksi protes terhadap pemerintah Myanmar agar dapat memberikan status kewarganegaraan agar etnis ini tidak mendapat perlakuan diskirminasi, mengingat Bangladesh juga merupakan negara yang dikunjungi pasca konflik dan membutuhkan bantuan karena banyak yang mengalami kelaparan dan kesehatan yang minim maka Indonesia juga ikut berupaya dalam membantu Rohingya melalui kebijakan luar negeri yang di lakukannya terhadap pemerintah Bangladesh

Rosenau memberikan tiga unit analisis dalam kebijkan luar negeri diantaranya adalah yang pertama bahwa kebijakan luar negeri harus memiliki orientasi, orientasi di sini adanya kesamaan sikap, persepsi dan nilai nilai yang berasal dari pengalaman historis dan lingkungan strategis dari masyarakat di dalam negara. dalam hal di atas Indonesia dan Bangladesh memiliki pengalaman historis yang cukup besar dimana Indonesia juga merupakan salah satu negara di Asia yang mengakui kemerdekaan Bangladesh

Pada tanggal 25 Februari 1972, Indonesia menjadi negara pertama yang menjalin hubungan diplomatik dengan Bangladesh, hal tersebut ditandai dengan pembukaan resmi kedutaan besar Republik Indonesia di Dhaka pada tanggal 1 Mei 1972, sejak saat itulah hubungan bilateral kedua negara terus mengalami pertumbuhan, berawal dari mantan presiden Bangladesh Ziaur Rahman, mengunjungi Indonesia di tahun 1978 dan kemudian presiden Soharto dari Indonesia juga yang mengunjungi bangladesh di tahun 1987 dan para petinggi negara terus melakukan kunjungan untuk memperkuat hubungan kedua negara, hingga pada akhirnya PM sheikh Hasina dari Bangladesh melakukan kunjungannya kembali ke Indonesia di tahun 2011 untuk menjadi ketua bersama dalam acara yang di senggarakan di Bali Democracy Forum (BDF) ke-4 yang dihadiri juga oleh Presiden Yudhoyono presiden ke-6 dari Indonesia ${ }^{16}$

${ }^{16}$ Embassy of Republic of Indonesia in Dhaka, (2019, 1 Juni) Bilateral Relations Indonesia - Bangladesh. Diakses melalui 
Hingga saat ini kerjasama pun masih terjalin di era presiden Jokowidodo, kedua negara melakukan perundingan dalam Preferential Trade Agreement (IB-PTA) di Dhaka, Bangladesh, hal tersebut dilakukan agar Indonesia dapat meningkatkan akses pasar ke negara-negara nontradisional. Pertemuan ini dianggap telah berhasil dilaksanakan setelah dipersiapkan dengan waktu yang tidak sedikit yaitu dalam kurun satu tahun yang sudah dilaksanakan setelah kedua kepala negara melakukan pertemuan di Dhaka pada 28 Januari 2018.. kedua negara berharap kerjasama terus dilakukan agar dapat meningkatkan perdagangan dan meningkakan juga perekonomian di kedua negara. selain itu juga Bangladesh merupakan pasar yang besar dan dianggap dapat memiliki pertumbuhan ekonomi sekitar 7,1 persen. ${ }^{17}$

Berdasarkan data dari badan pusat statistik (BPS), kedua negara memiliki total perdagangan sebesar US\$1,33 Miliar di tahun 2016, di tahun itu juga menjadi surplus bagi Indonesia dengan memperoleh sebesar US\$1,19 miliar. Di tahun 2018 tercatat ekspor Indonesia ke bangladesh mencapai U\$\$ 1,89 miliar dan naik sebesar 18,32 $\%$ jika dibandingkan dengan tahun sebelumnya yang hanya mencapai U\$\$ 89,46 juta. Bangladesh menempati urutan ke 23 sebagai negara yang menjadi tujuan ekpor dari Indonesia, sebesar 0,9 dan juga menjadi urutan ke 63 sumber impor utama di Indonesia dengan sebesar 0,1 persen $^{18}$ Selain itu juga Indonesia memiliki komoditas andalan dalam ekspor yang dilakukannya ke Bangladesh diantaranya adalah minyak kelapa

https://www.indonesia-

dhaka.org/indonesia-bangladesh-bilateralrelation/

${ }^{17}$ Kementerian Perdagangan RI, Catat Sejarah Baru,Indonesia dan Bangladesh Mulai Perundingan Pertama PT. Jakarta: Kemenerian Perdagangan. 2018.

18 Berita Satu (2019, 2 Juni). Indonesia Bangladesh sepakat Tingkatkan kerjasama Ekonomi. Diakses melalui https://www.beritasatu. com/dunia/475547/indonesiabangladeshsepakat-tingkatkan-kerja-sama-ekonomi sawit,briket, batu bara, dan bahan bakar yang padat yang dapat diproduksi dari batu bara, bubur kayu kimia, dan sulfat, di dalam bidang komoditas impor utama yang diterima Indonesia dari Bangladesh pada tahun 2018 yaitu kaos, rompi, benang rami, karung dan tas, Bangladesh mengimpor pakaian wanita, dan pakaian laki laki mulai dari usia dewasa maupun anak anak.

Selain membahas tentang kerjasama ekonomi, kedua kepala negara juga turut juga membahas bagaimana perkembangan situasi di negara bagian Rakhine di Myanmar, mengingat bahwa situasi di sana sangat memprerhatinkan, mulai dari adannya diskriminasi, kekerasan dan kelaparan akibat konflik, kedua negara menjadi penerima pengungsi khususnya etnis Rohingya yang memilih mengungsi ke Indonesia dan Bangladesh, kedua negara memiliki komitmen dalam membantunya dikarenakan mereka sama sama memiliki kesepakatan dalam ikut memberikan berkontribusina dalam membantu krisis kemanusiaan yang dihadapi Rohingya.

Yang kedua adalah kebijkan luar negeri sebagai komitmen dan aksi (foreign policy as a set of commitments to and plans for action). Indonesia memiliki komitmen dalam membantu pengungsi Rohingya berasaskan jiwa kemanusiaan, aksi yang dilakukan oleh Indonesia dalam membantu pengungsi Rohingya di Bangladesh ketika era presiden Jokowi Widodo telah menugaskan kementerian luar negeri RI untuk dapat pergi ke Dhaka, Bangladesh agar dapat mempersiapkan berbagai bantuan kemanusiaan terhadap etnis Rohingya Ketika tiba di sana, ibu. Retno melakukan pertemuan dengan Menteri Luar Negeri dari Bangladesh, yaitu Abul Hassan Mahood Ali. Ketika itu Ibu Retno Marsudi mengatakan bahwa untuk saat ini Indonesia akan terus memberikan dukungannya terhadap Bangladesh dan akan turut ikut membantu untuk mengakhiri krisis ini. ${ }^{19}$

\footnotetext{
${ }^{19} \mathrm{CNN}$ Indonesia (2018, 4 Desember). Di Bangladesh menlu Retno Bahas Pengungsi Rohingya. Diakses melalui https://www.cnnindonesia.com/internasiona 1/20170906002430-106-239-709/di-
} 
Presiden Joko Widodo telah mengapresiasi berbagai kerja sama yang sudah terjalin baik antara Indonesia dan Bangladesh. Hal itu disampaikan Presiden Jokowi saat menerima kunjungan kehormatan Menteri Luar Negeri Bangladesh Abul Hassan Mahmood Ali, pada tanggal 27 Januari 2018, yang dilakukan pertemuan di Hotel Pan Pacific Sonargaon, Dhaka Bangladesh. Selain itu juga kedua negara membicarakan hal yang cukup serius terutama yang berkaitan dengan isu Rohingya yang pada akhirnya Indonesia turut ikut mencoba dan berusaha meringankan sedikit beban yang dialami oleh Bangladesh dengan mengirimkan berbagai bantuan kemanusiaan terhadap pengungsi etnis Rohingya di Bangladesh. ${ }^{20}$ Presiden Md Abdul Hamid pada mencari dukungan dari Indonesia untuk ikut membantu pengembalian Rohingya yang aman dan memberikan bantuannya secara berkelanjutan. Hal tersebut dilakukan ketika Abdul Hamid mengunjungi Presiden Indonesia Joko Widodo dan dia mengatakan bahwa saat ini Bangladesh menampung lebih dari satu juta pengungsi Rohingya secara paksa dari Myanmar, Bangladesh telah melindungi mereka meskipun menghadapi banyak tantangan namun secara tidak langsung Bangladesh memiliki permasalahan diantaranya adalah perekonomiannya masih belum stabil dengan penduduk yang padat. ${ }^{21}$

Banyak juga dukungan dari lembaga kemanusiaan seperti Aksi Cepat Tanggap (ACT) dari Indonesia yang telahmemberikan bantuannya terhadap 50.000 pengungsi Rohingya di

bangladesh-menlu-retno-bahas-pengungsirohingya

20 Tribunnews (2018, 4 Desember). Menlu di Bangladesh apresiasi banuan indonesia unuk pengungsi Rakhine State. Diakses melaluihttp://www.tribunnews.com/tribunn ers/2018/01/28/menlu-bangladeshapresiasi-bantuan-indonesia-untukpengungsi-rakhine-state

21 Dhakatribune (2018, 27 November). President Hamid seeks Indonesia's support for safe Rohingya return. Diakses melalui https://www.dhakatribune.com/ bangladesh/2018/01/28/president-hamidindonesia-support-rohingya-return
Bangladesh. Pendistribusian terus menerus dilakukan berupa pangan dan alat kesehatan. ${ }^{22}$ Indonesia mendistribusikan terhadap 12 titik pos di wilayah pengungsi Rohingya di daerah Cox's Bazar, Hingga saat ini Indonesia sudah melakukan pengiriman 54 ton bantuan kemanusiaan yang tidak lain berupa 30 ton beras, 14.000 selimut, 2.004 paket makanan siap saji, 20 unit tenda besar, 10 unit tanki air fleksibel, 900 paket pakaian, dan satu ton gula pasir. ${ }^{23}$

Yang ketiga adalah kebijakan luar negeri sebagai Perilaku (foreign policy as a form of behaviour) dengan adanya aktivitas dan langkah nyata resmi yang berkaitan dengan peristiwa dan situasi tertentu dalam berinteaksi dengan aktor aktor lain, Indonesia telah melakukan interaksi dan aksi yang telah dilakukannya yang melibatkan kalangan masyarakat, organisasi internasional dan sebagainya dalam berkontribusi memberikan bantuan terhadap etnis Rohingya di Bangladesh yang pada akhrinya menandakan bahwa sifat atau perilaku dari Indonesia mencerminkan kepeduliannya terhadap etnis Rohingya, selain itu juga Indonesia merupakan negara yang memiliki jiwa kemanusiaan yang tinggi, padahal di satu sisi negara ini memiliki pemasalahan yang sama dalam mengatasi permasalahan penumpukan pengungsi yang datang ke negaranya. Bantuan yang diberikan juga terhadap pemerintah Bangladesh dapat meringankan beban pemerintah Bangladesh pengungsi Rohingya di negaranya tindakan yang dilakukan Indonesia juga dapat memperkecil korban yang berjatuhan di Bangladesh.

22 BBC Indonesia, (2018, 28 November). Bangladesh hadapi tanangan besar tangani Rohingya, bantuan indonesia sudah sampa. Diakses melalui https://www.bbc. $\mathrm{com} /$ indonesia/dunia-41226417

23 BBC Indonesia, (2018, 28 November) Bantuan Indonesia untuk Rohingya di Bangladesh 'mulai dibagikan hari ini'. Diakses melalui https://www.bbc. com/indonesia/indonesia-41302028 
102 Dzikiara Pesona Sadewa, Dudy Heryadi dan Taufik Hidayat | Kebijakan Luar Negeri Indonesia dalam Memberikan Bantuan Pengungsi Rohingya di Bangladesh

\section{Kesimpulan}

Berdasarkan hal di atas dapat ditarik kesimpulan bahwa dengan adanya konflik yang terjadi di Myanmar khsusnya di wilayah Rakhine telah menimbulkan pengungsi besar besaran dan terjadi peningkatan pengungsi etnis Rohingya di Bangladesh Pemerintah Bangladesh menanggapi masuknya para pengungsi secara positif dengan berfokus memberikan mereka tempat tinggal dan makanan serta kesehatan. Namun lama kelamaan pengungsi Rohingya mengalami peningkatan yang sangat pesat padahal Bangladesh pun adalah negara yang kecil dengan penduduk yang sangat tinggi. Indonesia menjadi negara yang memiliki permasalahan yang sama tentang pengungsi namun bisa mengatasi permasalahan Rohingya di negaranya. Indonesia juga adalah negara yang tergolong memiliki jiwa kemanusiaan yang sangat tinggi sehingga negara ini juga ikut berperan membantu pemerintah Bangladesh terutama terhadap etnis Rohingya yang mengalami masalah kelaparan.

\section{Daftar Pustaka}

\section{Berita}

BBC News, diakses melalui https:// www. bbc/Indonesia/dunia-41139299 [diakses pada 29 November 2018]

BBC Indonesia, Bangladesh hadapi tanangan besar tangani Rohingya, bantuan Indonesia sudah sampai diakses melalui https:// www.bbc. com/ Indonesia/ dunia41226417 [diakses 28 November 2018]

BBC Indonesia, Bantuan Indonesia untuk Rohingya di Bangladesh 'mulai dibagikan hari ini' diakses melalui https://www.bbc. com/ Indonesia/ Indonesia-41302028 [diakses 28 November 2018]

Berita Satu Indonesia Bangladesh sepakat Tingkatkan kerjasama Ekonomi diakses melalui https://www.beritasatu. com / dunia/475547/Indonesiabangladesh- sepakat-tingkatkan-kerja-sama-ekonomi [diakses 2 Juni 2019]

CNN Indonesia, di Bangladesh menlu Retno Bahas Pengungsi Rohingya diakses melalui https://www. cnn Indonesia. com/internasional/20170906002430-10 62397 09/di-bangladesh -menlu-retnobahas-pengungsi-rohingya [4 Desember 2018]

Dhakatribune, President Hamid seeks Indonesia's support for safe Rohingya return diakses melalui https://www. dhakatribune. com/ bangladesh/ 2018/01/28/president-ha mid-Indonesiasupport-rohingya-return [27 Desember 2018]

Embassy of Republic of Indonesia in Dhaka, Bilateral Relations Indonesia Bangladesh diakses melalui https:// www.Indonesia-dhaka.org/ Indonesia bangladesh-bilateral-relation/ [Diakses 1 Juni 2019]

The World Bank Bangladesh World Development Indicators diakses melalui http://data.worldbank.org/country/bangla desh [Diakses 1 Juni 2019]

The Guardian News, Un report on Rohingya hunger is shelved at Myanmar's request diakses melalui https:// www.theguardian. com/ world /2017 /oct/17/un-report-on-rohingya hunger is-shelved-atmyanmars-request [Diakses 25 November 2018]

Tribunnews, Menlu di Bangladesh apresiasi banuan Indonesia unuk pengungsi Rakhine State diakses melaluihttp://www.tribunnews.com/ tribunners/2018/01/28/menlu-bangla desh-apresiasi-bantuan-Indonesia-untukpengungsi-rakhine-state [Diakses 4 Desember 2018] 
103 Dzikiara Pesona Sadewa, Dudy Heryadi dan Taufik Hidayat | Kebijakan Luar Negeri Indonesia dalam Memberikan Bantuan Pengungsi Rohingya di Bangladesh

\section{Buku}

Rosenau, James N. 1976. World Politics; an introduction. New York: The Free Press

Susetyo, Aryanto, \& Wasti. 2013. Rohingya Suara Etnis yang Tidak Boleh Bersuara, Jakarta: PAHAM Indonesia

\section{Jurnal dan karya tulis}

Chit and Thomas Kean, 2017. "Communal Conflict in Myanmar: The Legislature's Response." Journal of Contemporary Asia 47 (3). DOI: $10.1080 / 004723$ 36.2017 .129184

Dean, Richard. 2006. The Value of Humanity: in Kan't Moral Theory. Oxford: Clarendon Press

Sari, Deasy Silviya. Hidayat Taufik, dan Pratisti Aliyuna. 2018. Indonesian Government Policy on Rohingya Refugees Andalas Journal of International Studies VII (1)

Fautanu, Idzam. 2007. Konsep Negara Islam Muhammad Assad: Studi Atas Pemikiran dan Kontribusinya Terhadap Pakistan Jakarta: UIN Syarif Hidayatullah.

Haryanto, Agus (2014) Prinsip Bebas Aktif Dalam Kebijakan Luar Negeri Indonesia : perspekif Teori Peran "Jurnal Ilmu Politik dan Komunikasi, Universitas Komputer Indonesia IV (II)

Islam, Mohammad Mainul \& Nuzhath Tasmiah. 2018. Health risks of Rohingya refugee population in Bangladesh: a call for global attention." Department of Population Sciences, University of Dhaka.

Medecins Sans Fronieres (MSF). 2012, 10 years For The Rohingya Refugees in Bangladesh, Past Present And Future
Sari, Deasy Silvya. 2018. Kebijakan Luar Negeri Indonesia Terhadap Mesir Pasca Pemerintahan Husni Mubarak, Bandung: Universitas Padjadjaran.

Situmorang, Mangadar 2015, Orientasi Kebijakan Politik Luar Negeri Indonesia di bawah Pemerintahan Jokowi-JK. Jurnal Ilmiah Hubungan Internasional 11 (1). DOI: https://doi.org/10.26593/jihi.v11i1.1442.\%2 $5 \mathrm{p}$

Trust Fund for Human Security, Human Security in Theory and Practice, Application of the Human Security Concept and the United Nation

\section{Laporan}

Inter Sector Coordination Group (ISCG). 2019. Situation Report Rohingya Refugee Crisis, Cox's Bazar,

Kementerian Perdagangan Republik Indonesia. 2018. Kemenerian Perdagangan RI, Catat Sejarah Baru,Indonesia dan Bangladesh Mulai Perundingan Pertama PTA,

Seva Fondation And The international Agency For The Prevention Of Blindness (IAPB). 2018. A Situational Analysis : eye Care needs Of Rohingya Refugees and The affected Bangladesh Host Population in cox's Bazar District Bangladesh

United Nations. Development Programme. (UNDP). 1994. Human Development Reports New York: Oxford University Press. 